\title{
The functional role of individual-alpha based frontal asymmetry in stress responding
}

Citation for published version (APA):

Quaedflieg, C. W. E. M., Meyer, T., Smulders, F. T. Y., \& Smeets, T. (2015). The functional role of individual-alpha based frontal asymmetry in stress responding. Biological Psychology, 104, 75-81. https://doi.org/10.1016/j.biopsycho.2014.11.014

Document status and date:

Published: 01/01/2015

DOI:

10.1016/j.biopsycho.2014.11.014

Document Version:

Publisher's PDF, also known as Version of record

Document license:

Taverne

Please check the document version of this publication:

- A submitted manuscript is the version of the article upon submission and before peer-review. There can be important differences between the submitted version and the official published version of record.

People interested in the research are advised to contact the author for the final version of the publication, or visit the DOI to the publisher's website.

- The final author version and the galley proof are versions of the publication after peer review.

- The final published version features the final layout of the paper including the volume, issue and page numbers.

Link to publication

\footnotetext{
General rights rights.

- You may freely distribute the URL identifying the publication in the public portal. please follow below link for the End User Agreement:

www.umlib.nl/taverne-license

Take down policy

If you believe that this document breaches copyright please contact us at:

repository@maastrichtuniversity.nl

providing details and we will investigate your claim.
}

Copyright and moral rights for the publications made accessible in the public portal are retained by the authors and/or other copyright owners and it is a condition of accessing publications that users recognise and abide by the legal requirements associated with these

- Users may download and print one copy of any publication from the public portal for the purpose of private study or research.

- You may not further distribute the material or use it for any profit-making activity or commercial gain

If the publication is distributed under the terms of Article $25 \mathrm{fa}$ of the Dutch Copyright Act, indicated by the "Taverne" license above, 


\title{
The functional role of individual-alpha based frontal asymmetry in stress responding
}

\author{
C.W.E.M. Quaedflieg*, T. Meyer, F.T.Y. Smulders, T. Smeets \\ Faculty of Psychology and Neuroscience, Maastricht University, P.O. Box 616, 6200 MD Maastricht, The Netherlands
}

\section{A R T I C L E I N F O}

\section{Article history:}

Received 21 August 2014

Accepted 26 November 2014

Available online 4 December 2014

\section{Keywords:}

Frontal alpha oscillations

Individual alpha frequency

Cortisol

EEG

\begin{abstract}
A B S T R A C T
Asymmetry in frontal electrical activity has been suggested to index tendencies in affective responding and thus may be associated with hormonal stress responses. To assess the functional role of frontal asymmetry (FA) in stress, we measured FA at rest and following exposure to acute stress induced with the Maastricht Acute Stress Task (MAST; $N=70$ ) in the standard $8-13 \mathrm{~Hz}$ band as well as based on individual alpha frequency (IAF) band. IAF-based resting FA $\mathrm{F}_{\mathrm{F} 4 \mathrm{~F} 3}$ was associated with the stressinduced neuroendocrine response, such that left individual frontal activity predicted smaller total cortisol increases in response to the MAST. Like previous studies, we found resting left-sided FAF8-F7 to predict trait behavioural activation measured with the BIS/BAS scales. FA remained unaffected by stress-induced cortisol response. These findings suggest that individual FA might reflect a trait-like characteristic that moderates the stress response. Our results underscore the utility of IAF in studying individual differences in stress responding.
\end{abstract}

(c) 2014 Elsevier B.V. All rights reserved.

\section{Introduction}

Research suggests that a functional lateralization in the prefrontal cortex is involved in affective processing (Coan, Allen, \& McKnight, 2006; Davidson, 2004; Harmon-Jones, Gable, \& Peterson, 2010; Heller, 1993). A reliable correlate of frontal activity is frontal asymmetry (FA) measured with electroencephalography (EEG). FA refers to the average difference in alpha-band activity (typically $8-13 \mathrm{~Hz}$ ) between the left and right frontal areas across several minutes. FA measured while participants are at rest has been regarded as an index of individuals' trait-like style of affective processing, whereas FA measured during or after emotional challenge has been linked to state-dependent individual differences in affective processing (Coan \& Allen, 2003b; Coan \& Allen, 2004; Coan et al., 2006; Goodman, Rietschel, Lo, Costanzo, \& Hatfield, 2013; Perez-Edgar, Kujawa, Nelson, Cole, \& Zapp, 2013). For instance, more left-sided resting FA (i.e., higher activity in the left hemisphere) has been linked to superior emotional flexibility (Papousek, Reiser, Weber, Freudenthaler, \& Schulter, 2012), more effective emotion regulation (Jackson et al., 2003) as well as to more positive and decreased negative affect (Tomarken, Davidson, Wheeler,

\footnotetext{
* Corresponding author. Tel.: +31 433884536 .

E-mail address: conny.quaedflieg@maastrichtuniversity.nl (C.W.E.M. Quaedflieg).
}

\& Doss, 1992). Furthermore, an association between right-sided FA and higher basal cortisol levels has been found in animal studies at baseline (Kalin, Larson, Shelton, \& Davidson, 1998) and after maternal separation (Rilling et al., 2001) as well as in human studies in six-month-old infants at baseline and during a withdrawal task (Buss et al., 2003) and in students during a stressful exam period (Hewig et al., 2008).

While these findings suggest that resting FA may be predictive of stress hormonal responses, other lines of research indicate that the stress response itself might involve lateralized processes in the brain. That is, animal and human studies suggest that the right hemisphere initiates neuroendocrine and behavioural fight-orflight responses, while the left hemisphere regulates them (Baeken et al., 2014; Davidson, 2000; Lueken et al., 2009; Sullivan \& Gratton, 2002; Sullivan, 2004; Wittling \& Pfluger, 1990). Right-sided FA at rest and in response to stress could thus be expected to predict stronger hormonal stress responses. However, to date, only three experimental studies have examined the relationship between FA, stress, and stress hormonal responses, and have yielded mixed results. Tops et al. (2005) found that the administration of cortisol shifted the relative FA to the right. In a follow-up study, however, these authors found that cortisol administration in a formal and arousing testing condition shifted FA to the left (Tops, van Peer, Wester, Wijers, \& Korf, 2006). Alternatively, Lewis, Weekes, and Wang (2007) found that high in comparison to low examination stress increased relative right-sided FA activity. 
Previous research has shown that alpha frequency varies in peak and bandwidth from individual to individual (Bazanova \& Vernon, 2014; Doppelmayr, Klimesch, Pachinger, \& Ripper, 1998; Gasser, Bacher, \& Steinberg, 1985; Tomarken, Davidson, Wheeler, \& Kinney, 1992). Moreover, individual differences in alpha peak frequency have been related to several cognitive functions including perception, attention, memory (Klimesch, Schimke \& Pfurtscheller 1993; for review see Klimesch, 1999). Thus, the use of fixed frequency bands in previous studies may have obscured information about specific individual differences in neurophysiology of the brain. Using individual alpha frequency bands could potentially improve the signal-to-noise ratio and thus improve reliability of FA measurements.

In the current study, we used the Maastricht Acute Stress Task (MAST: Smeets et al., 2012) to induce neuroendocrine stress responses and investigated the functional role of asymmetric frontal alpha oscillations. Based on previous studies, it was hypothesized that more right-sided FA at rest and in response to stress, would be related to higher cortisol increases in response to the MAST. Furthermore, it was expected that FA at rest would be associated with level of trait motivation. The second aim of the study was to examine whether FA based on an individualized alpha frequency band can provide a more sensitive measure of individual differences in lateralized stress responding.

\section{Methods}

\subsection{Participants}

The present experiment was part of a larger study that investigated frontal alpha asymmetry and resilience. Right-handed healthy male $(n=30)$ and female $(n=40)$ undergraduates (mean age: 20.83 SD 2.67; range: 18-31 years) were recruited via advertisements at Maastricht University. Participants were screened for eligibility using the following exclusion criteria: history of psychiatric, neurologic, cardiovascular or neuroendocrine diseases, heavy smoking (i.e., more than 15 cigarettes/day), medication use known to affect the autonomic nervous system (ANS) or hypothalamic-pituitary-adrenal (HPA) axis, drug use, or body mass index outside the normal range. Moreover, for women, the use of oral contraceptives served as an inclusion criterion to reduce variability in cortisol responses related to hormonal alterations throughout the menstrual cycle phase (e.g., Kudielka, Hellhammer, \& Wust, 2009). Test protocols were approved by the standing ethics committee of the Faculty of Psychology and Neuroscience, Maastricht University. All participants signed a written informed consent and were given a small reward (course credits or money) in return for their participation.

\subsection{Procedure}

An overview of the experimental session is displayed in Fig. 1. All testing took place between $12: 30$ and $18: 00 \mathrm{~h}$ to avoid morning fluctuations in the circadian rhythm of cortisol and time-of-day effects on frontal asymmetry (Velo, Stewart, Hasler, Towers, \& Allen, 2012). Beforehand, participants were asked via email to refrain from eating, exercising extensively or drinking anything but non-sparkling water for $2 \mathrm{~h}$ prior to the experimental session. Upon arrival in the laboratory, participants received information on the experimental procedure and gave written consent. Next, a saliva sample was taken and participants were told that this sample would be immediately assayed to check their adherence to the instructions not to eat, drink, etc. This was done to increase truth-telling behaviour. In reality, the sample was discarded without being analyzed. Participants were seated in front of a 22-in. widescreen monitor (Philips, The Netherlands) at approximately $56 \mathrm{~cm}$ viewing distance and drank $200 \mathrm{ml}$ of apple juice to standardize glucose levels (Kudielka, Hellhammer, \& Kirschbaum, 2007).

\subsection{Stress manipulation}

The Maastricht Acute Stress Test (MAST: Smeets et al., 2012) consists of a 5 min preparation phase in which the task is explained and a 10 min acute stress phase that includes several exposures to cold pressor stress and various mental arithmetic challenges along with social-evaluative pressure (i.e., negative feedback). Specifically, in 5 trials that varied in duration from 60 to $90 \mathrm{~s}$, participants immersed their hand into ice-cold water $\left(2^{\circ} \mathrm{C}\right.$; plexiglas box with an electrical cooler and a circulation pump from JULABO Labortechnik, Seelbach, Germany). In between the hand immersion trials, participants engaged in mental arithmetic challenges in which they had to count backwards as fast and accurately as possible in steps of 17 starting at 2043 for 45,60 or $90 \mathrm{~s}$. Whenever they counted too slowly or made a mistake, they received negative feedback (i.e., to count faster or start over again at 2043).
To increase unpredictability and uncontrollability, participants were told that the order and duration of the hand immersion and mental arithmetic trials would be randomly chosen by the computer and that they would be videotaped.

\subsection{Neuroendocrine stress responses}

Cortisol values prior to and in response to the MAST were obtained with synthetic Salivettes (Sarstedt ${ }^{\circledR}$, Etten-Leur, The Netherlands). Participants provided saliva samples $20 \mathrm{~min}$ after arrival in the lab ( $\left.t_{\text {base }}\right), 5$ min before $\left(t_{\text {pre-stress }}\right)$ the MAST and 5 times afterwards $\left(t_{+0}, t_{+10}, t_{+30}, t_{+40}, t_{+55 \text { min }}\right.$ with reference to the end of the stressor). Samples were stored at $-20^{\circ} \mathrm{C}$ until cortisol levels were determined by a commercially available luminescence immune assay kit (IBL, Hamburg, Germany). Mean intra- and inter-assay coefficients of variation are typically less than $5 \%$, and the lower and upper detection limits were $0.015 \mathrm{mg} / \mathrm{dl}(0.41 \mathrm{nmol} / \mathrm{l})$ and $4.0 \mathrm{mg} / \mathrm{d}$ $(110.4 \mathrm{nmol} / \mathrm{l})$, respectively. One female participant did not provide enough saliva to be analyzed. Thus, the final sample consisted of 69 participants.

Cortisol after arrival in the lab ( $\left.t_{\text {base }}\right)$ and before the MAST ( $\left.t_{\text {pre-stress }}\right)$ did not differ significantly $\left(F_{(1,64)}=1.91, p=0.17\right)$. For the correlations, the Area Under the Curve with respect to increase (AUCi) from the pre-stress sample was calculated as a single measure of the total cortisol concentration in response to the MAST for each participant individually (cf. Pruessner, Kirschbaum, Meinlschmid, \& Hellhammer, 2003).

\subsection{Approach behaviour}

Behavioural Inhibition and Activation System Scales (BIS/BAS scales; Carver \& White, 1994). The BIS/BAS Scales were used to assess a person's disposition towards the two motivational systems i.e., approach and withdrawal. The questionnaire consists of 22 items assessing behavioural inhibition (BIS; 7 items) and behavioural activation (BAS; 13 items). The BAS is further divided into three subscales: fun seeking (BAS-F; 4 items), reward responsiveness (BAS-R; 5 items), and drive (BAS-D; 4 items). Participants answer the extent to which they agree with the statements on a four-point Likert-type scale, ranging from 1 (strong agreement) to 4 (strong disagreement). Higher scores relate to higher BIS/BAS sensitivity.

\subsection{EEG data acquisition and analysis}

The electroencephalogram (EEG) was recorded from $23 \mathrm{Ag} / \mathrm{AgCl}$ electrodes (F7, F3, Fz, F4, F8, FC3, FC4, T7, T8, C3, Cz, C4, CP3, CPz, CP4, P7, P3, Pz, P4, P8, O1, Oz, $\mathrm{O} 2$ ) positioned in an elastic cap according to the international $10-20$ system using a BrainAmp amplifier and Brain Recorder software (BrainProducts, Germany). Signals were sampled continuously at $100 \mathrm{~Hz}$, referenced online to the left mastoid (A1) and band-pass filtered $(0.01-30 \mathrm{~Hz})$. An electrode at AFz served as signal ground. Two electrodes at the outer canthi of both eyes recorded horizontal eye movements and two electrodes above and below the left eye recorded vertical eye movements. Scalpelectrode impedance was kept below $5 \mathrm{k} \Omega$ to ensure high-quality EEG recordings and homologous scalp electrodes were within $1 \mathrm{k} \Omega$ of each other. Participants were shown the raw recording signals to demonstrate common artefacts that occur due to body and eye movements. FA was measured before and after stress induction during two 4 min blocks, whereby participants focused on a black fixation cross on grey background on the computer monitor.

Offline analyses were performed with Vision Analyzer 2.0 (Brain Products, Germany). Consistent with data reduction procedures in previous FA studies (e.g. Meyer et al., 2014; for review see Allen, Coan, \& Nazarian, 2004), the data was rereferenced offline to the average of $\mathrm{A} 1$ and $\mathrm{A} 2$, band-pass filtered from 1 to $30 \mathrm{~Hz}$ and corrected for EOG activity using an algorithm similar to Gratton, Coles, and Donchin (1983). To derive resting-state FA scores, 2 s epochs with 75\% overlap were extracted. Epochs containing EEG changes exceeding $\pm 75 \mu \mathrm{V}$ were automatically omitted from averages. On average 955.61 (range $=895-1005$; $\mathrm{SEM}=2.49$ ) of baseline and 963.67 (range $=913-1020 ;$ SEM $=2.10$ ) of post stress epochs were artefact free. Artefact-free epochs were analyzed using fast-Fourier transformation (FFT) with a $100 \%$ Hanning window to compute power density values. Average power densities of the two 4 min resting state measurements were calculated and weighted for the number of artefact-free epochs for both the baseline and the post-stress measurement.

The individual alpha peak frequency (IAF) was determined as the dominant frequency rhythm between 5 and $15 \mathrm{~Hz}$ at the posterior electrode $(\mathrm{Pz})$ on $3 \mathrm{~min}$ of resting eyes closed data (Doppelmayr et al., 1998; Klimesch, 1999). The IAF bandwidth was defined as the IAF $\pm 0.20 \times$ IAF. The asymmetry scores were based on the IAF band and on the standard alpha band between 8 and $13 \mathrm{~Hz}$ (FA) and were calculated on log-transformed alpha-power density values, $\ln$ (right) $-\ln$ (left). Positive alpha asymmetry scores indicate greater left than right frontal activity since alpha band power is inversely related to brain activity (Pfurtscheller, Stancak, \& Neuper 1996).

\subsection{Data analysis}

Cortisol data were log-transformed before analysis as Shapiro-Wilk tests of normality showed typical positive skewness of the data. Effectiveness of the stress induction procedure on neuroendocrine measures including differences between men and women were addressed using repeated measures ANOVA with time (6 


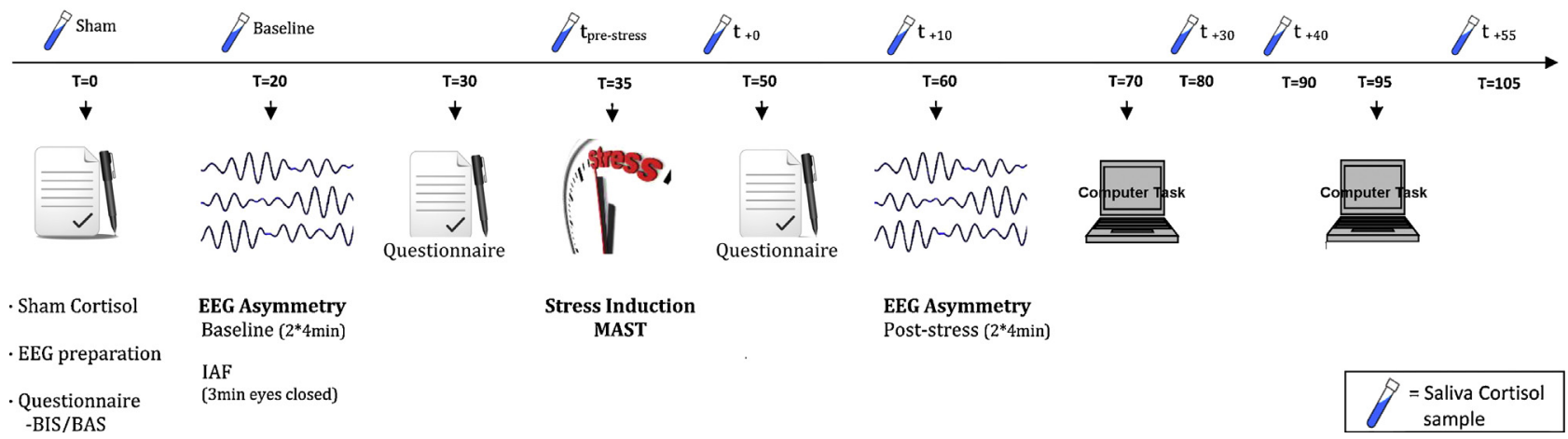

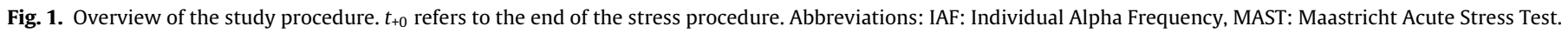

levels: $t_{\text {pre-stress }} t_{+0}, t_{+10}, t_{+30}, t_{+40}, t_{+55 \text { min }}$ ) as within subject variable and gender as between subject variable. Effects of the stress on FA as well as differences between men and women were addressed using repeated measures ANOVA with manipulation (baseline, post-stress) and location (F4-F3, F8-F7) as within subject variables and gender as between subject variable. To explore possible relationships between participants' physiological stress response (i.e., AUCi) and brain asymmetry, bivariate Pearson correlations were conducted. We used a hypothesis driven approach (i.e., including asymmetry scores at frontal electrodes only) to limit the inflation of Type I error rates in these analyses and corrected for multiple testing (i.e., F4-F3 and F8-F7) by using a significance level of $p \leq 0.025$. When sphericity assumptions for ANOVAs were violated, Greenhouse-Geisser corrected $p$-values, along with the respective epsilon and uncorrected degrees of freedom are reported.

\section{Results}

\subsection{Stress manipulation: neuroendocrine responses}

Mean cortisol concentrations prior to and following the MAST are shown in Fig. 2. Repeated measures ANOVAs revealed a significant time $\times$ gender interaction $\left(F_{(5,310)}=5.09, p=0.004\right.$, Epsilon $=0.48)$. Follow-up analyses per gender reveal a main effect of time ( 6 levels: $t_{\text {pre-stress }}, t_{+0}, t_{+10}, t_{+30}, t_{+40}, t_{+55 \text { min }}$; Males: $F_{(5,130)}=22.84, p<0.001$, Epsilon $=0.44 ;$ Females: $F_{(5,180)}=8.14$,

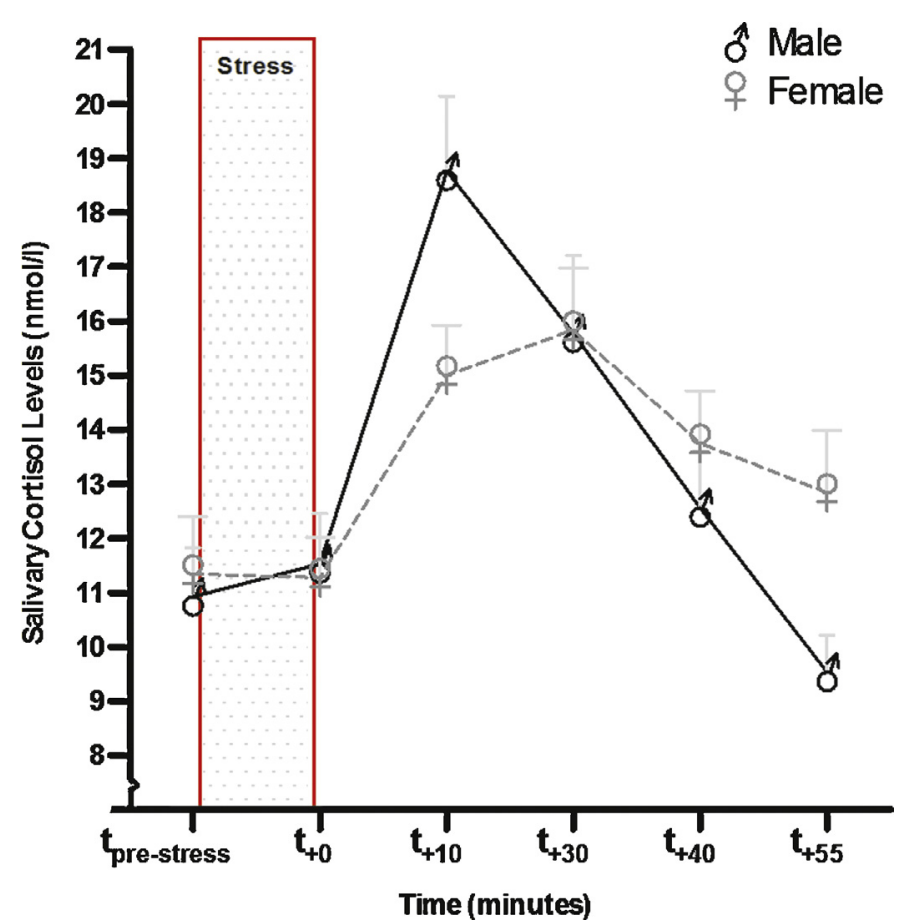

Fig. 2. Salivary cortisol responses to the Maastricht Acute Stress Test (MAST). Graphs show mean $\pm S E$. $p<0.001$, Epsilon =0.44). Bonferroni corrected simple effects per saliva time point revealed a significant increase between $t_{\text {pre-stress }}$ and $t_{+10}$ (males: $p<0.001$; females: $p=0.01$ ) and a significant decrease between $t_{+30}$ and $t_{+40}$ (males: $p<0.001$; females: $p<0.001$ ) to a return to baseline at the end of the experiment $\left(t_{\text {pre-stress }} v s t_{+55}\right.$ males: $p>0.99$; females: $p>0.99$ ).

\subsection{Frontal asymmetry: standard vs individual alpha}

The mean of the IAF was $9.98 \mathrm{~Hz}$ (SEM 0.11 ; minimum $=7.4$ maximum $=11.3$ ) and was not statistically different from the centre $(10 \mathrm{~Hz})$ of the standard alpha band $\left(F_{(1,50)}=0.05, p=0.82\right)$. Bivariate Pearson correlations were conducted between the first and second block of the baseline $\mathrm{FA}_{\mathrm{F} 4-\mathrm{F} 3}$ for the standard and IAF band separately to evaluate whether IAF-based FA yielded higher (test-retest) reliability scores than the standard $8-13 \mathrm{~Hz}$ alpha band. The standard alpha $(8-13 \mathrm{~Hz})$ based baseline $\mathrm{FA}_{\mathrm{F} 4-\mathrm{F} 3}$ correlation between the two four minute blocks was $r_{67}=0.70$ and the IAF-based FA correlation was $r_{67}=0.85$. These correlations were significantly different (baseline: $Z=-2.22, p=0.026$, two-tailed) indicating a better test-retest stability for IAF-based $F A_{F 4-F 3}$.

\subsection{Frontal asymmetry and stress induction}

For the mean power density values based on standard alpha band $(8-13 \mathrm{~Hz})$, repeated measures ANOVA with manipulation (baseline, post-stress) and location (F4-F3, F8-F7) as within subject variables and gender as between subject variable revealed no significant interactions and only a main effect of location $\left(F_{(1,67)}=25.84, p<0.001\right)$. Likewise, for the IAF-based FA, no significant interactions and only a main effect of location $\left(F_{(1,67)}=25.69\right.$, $p<0.001$ ) was found, indicating that stress did not directly affect frontal asymmetry ${ }^{1}$ (see Fig. 3 ).

\subsection{Frontal asymmetry, neuroendocrine response and behavioural activation}

Bivariate Pearson correlations between participants' physiological stress response and brain asymmetry were computed. Table 1 displays the correlations between total cortisol concentration (AUCi) and the standard alpha band $(8-13 \mathrm{~Hz})$ and IAF for baseline, post-stress and stress-reactivity (i.e., Asym baseline - Asym $_{\text {post-stress }}$ ) asymmetry measures. For IAF-based baseline F4-F3 asymmetry, a negative correlation $\left(r_{67}=-0.27 ; p=0.025\right)$ was found, showing

\footnotetext{
1 Hemisphere specific stress effects were assessed using a MANOVA with manipulation (baseline, post-stress) and hemisphere (left, right) as within subject variables and gender as between subject variable. No manipulation $\times$ hemisphere interaction was found $\left(F_{(1,67)}=2.58, p=0.12\right)$.
} 

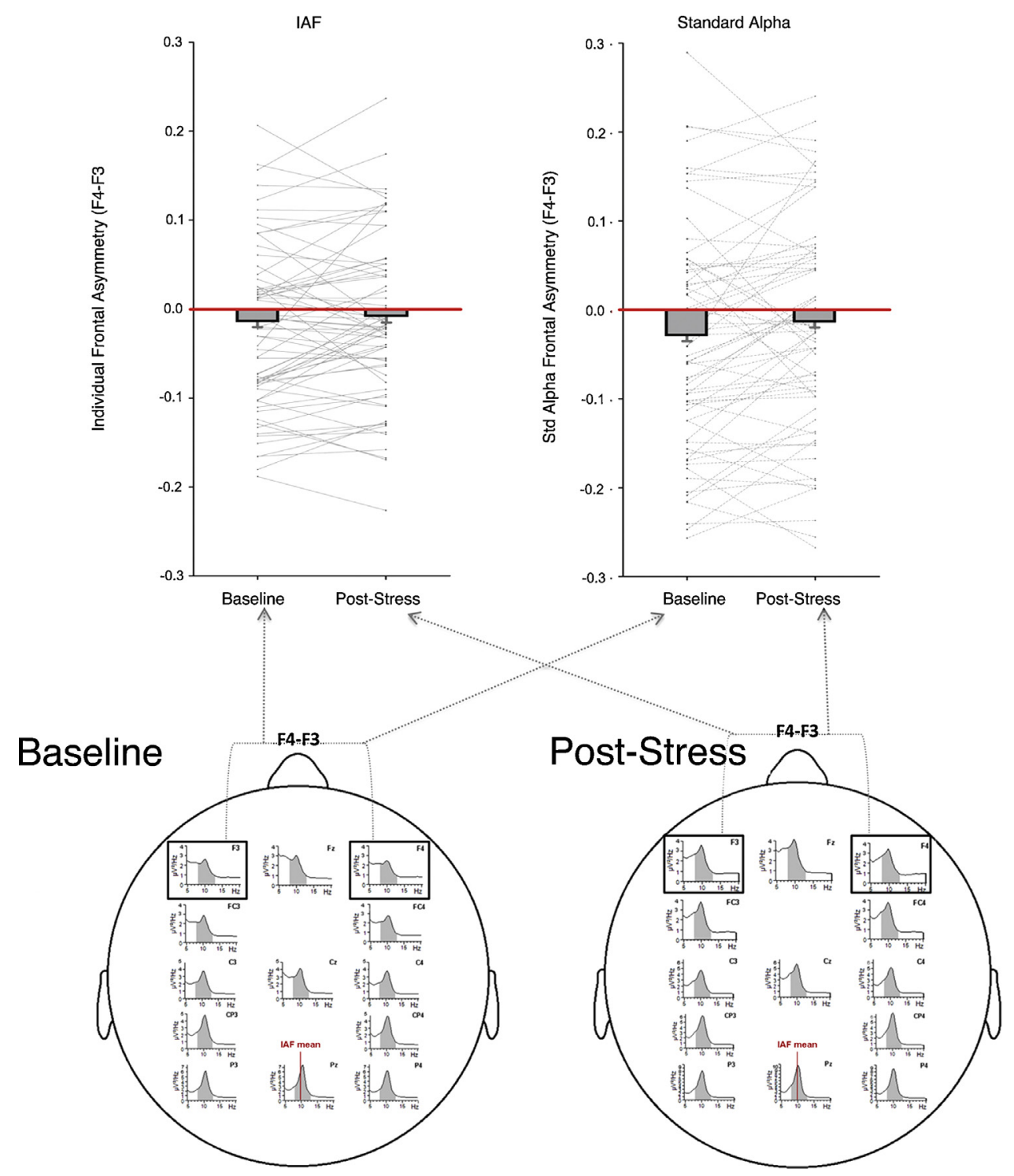

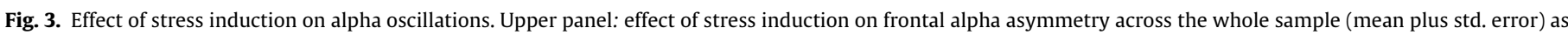

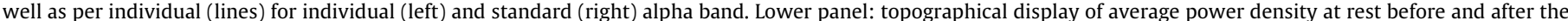

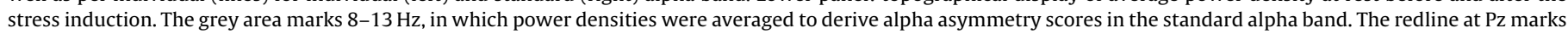
the mean IAF. Note the difference in $Y$-axis scaling between frontal and parietal electrodes.

that more left-sided frontal activity at baseline was associated with a smaller cortisol response to the stressor (see Fig. 4). Meanwhile, the association with $\mathrm{FA}_{\mathrm{F} 4-\mathrm{F} 3}$ post-stress based on IAF was at trend level $\left(r_{67}=-0.24 ; p=0.05\right)$. However, the associations with $\mathrm{FA}_{\mathrm{F} 4-\mathrm{F} 3}$ baseline and post-stress based on standard alpha remained nonsignificant (baseline: $r_{67}=-0.21 ; p=0.08$; post-stress: $r_{67}=-0.20$; $p=0.10$ ). Moreover, the IAF associations for baseline and poststress FA were specific for the mid-frontal electrodes (F4-F3) since all other correlations were non-significant (all ps $>0.78$ ). Stress-reactivity FA did not correlate significantly with the cortisol response, for both standard alpha and IAF (all $p s>0.68$, see Table 1$)^{2}$

Measures of behavioural activation and inhibition (BIS/BAS) were correlated with brain asymmetry. For both baseline

2 Bivariate Pearson correlations between the cortisol response immediately before the frontal asymmetry measurement (i.e., $t_{+10}$ ) and brain asymmetry were nearly identical (IAF: $r_{69}=-0.25 ; p=0.04$; std. alpha $r_{69}=-0.22 ; p=0.08$ ).

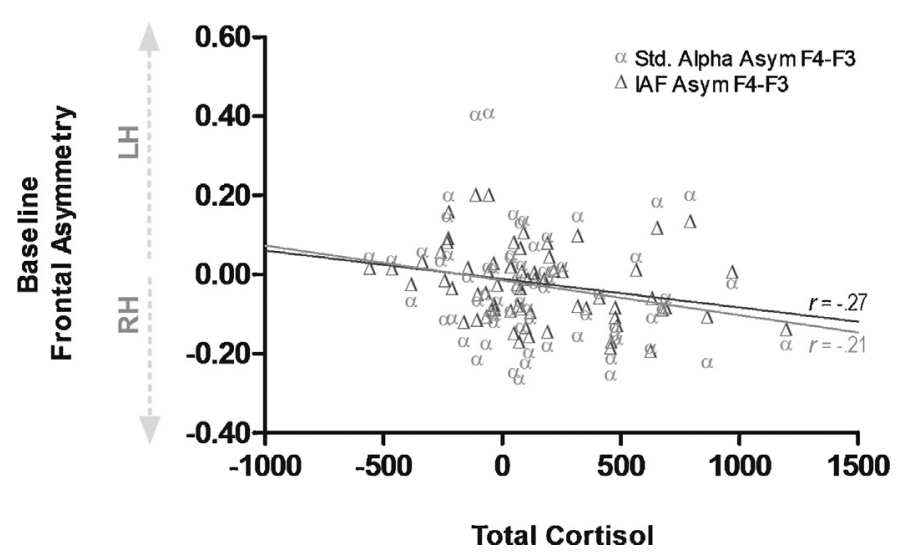

Fig. 4. Association between baseline asymmetry at F4-F3 and total cortisol response. More right-sided asymmetry resulted in a higher cortisol increase. Note that the correlation was only significant for IAF. 
Table 1

Summary of the EEG results. Upper part: mean \pm SEM of the frontal asymmetry before and after stress induction for F4-F3 and F8-F7 separately based on $8-13 \mathrm{~Hz}$ or IAF. Lower part: associations between the cortisol response and brain asymmetry based on $8-13 \mathrm{~Hz}$ or IAF.

\begin{tabular}{|c|c|c|c|c|}
\hline & \multicolumn{2}{|c|}{ Standard Alpha $8-13 \mathrm{~Hz}$} & \multicolumn{2}{|c|}{ Individual Alpha } \\
\hline & Mean & SEM & Mean & SEM \\
\hline \multicolumn{5}{|l|}{ Baseline } \\
\hline Asym $_{\mathrm{F} 4-\mathrm{F} 3}$ & -0.024 & 0.018 & -0.022 & 0.011 \\
\hline Asym $_{\mathrm{F} 8-\mathrm{F} 7}$ & -0.186 & 0.037 & -0.118 & 0.024 \\
\hline \multicolumn{5}{|l|}{ Post-stress } \\
\hline Asym $_{\mathrm{F} 4-\mathrm{F} 3}$ & -0.010 & 0.017 & -0.012 & 0.011 \\
\hline \multirow[t]{3}{*}{ Asym $_{F 8-F 7}$} & -0.159 & 0.034 & -0.112 & 0.023 \\
\hline & \multicolumn{2}{|c|}{ Total Cortisol (AUCi) } & \multicolumn{2}{|c|}{ Total Cortisol (AUCi) } \\
\hline & $r$ & $p$ & $r$ & $p$ \\
\hline \multicolumn{5}{|l|}{ Baseline } \\
\hline Asym $_{\mathrm{F} 4-\mathrm{F} 3}$ & -0.21 & 0.08 & -0.27 & 0.025 \\
\hline Asym $\mathrm{F8-F7}$ & 0.006 & 0.96 & -0.03 & 0.78 \\
\hline \multicolumn{5}{|l|}{ Post-stress } \\
\hline Asym $_{\mathrm{F} 4-\mathrm{F} 3}$ & -0.20 & 0.10 & -0.24 & 0.05 \\
\hline Asym $68-\mathrm{F7}$ & 0.03 & 0.79 & -0.03 & 0.84 \\
\hline \multicolumn{5}{|c|}{ Stress-reactivity } \\
\hline Asym $_{\mathrm{F} 4-\mathrm{F} 3}$ & 0.03 & 0.80 & 0.03 & 0.82 \\
\hline Asym $_{\mathrm{F} 8-\mathrm{F} 7}$ & 0.05 & 0.68 & 0.02 & 0.85 \\
\hline
\end{tabular}

Note: Stress-reactivity is the change in FA (i.e., post-stress - baseline).

$p$-Values $\leq .025$ were considered as statistically significant.

asymmetry measures of Asym $\mathrm{F}_{\mathrm{F}-\mathrm{F} 7}$, a positive correlation with BAS drive (IAF: $r_{60}=0.35 ; p=0.006$; Standard Alpha: $r_{60}=0.32 ; p=0.01$ ) and a negative correlation with BIS (IAF: $r_{60}=-0.33 ; p=0.01$; Standard Alpha: $\left.r_{67}=-0.30 ; p=0.02\right)$ was found, indicating that more left-sided frontal activity at baseline was associated with more behavioural activation (see Fig. 5). The association with FA was specific for the lateral frontal electrodes (F8-F7) since all other correlations were non-significant (all ps>0.10). Bivariate Pearson correlations between BIS/BAS and stress-reactivity FA did not reveal any significant associations for both standard alpha and IAF (all ps >0.21). Bivariate Pearson correlations between BIS/BAS and the participants' physiological stress response did not reveal any significant associations (all ps $>0.17$ ).

\section{Discussion}

The aim of the current study was to investigate the functional role of asymmetric frontal alpha oscillations in stress-induced neuroendocrine responses. Secondly, we explored whether the relationship between FA and individual differences in stress responding are more reliably described if based on IAF instead of the standard $8-13 \mathrm{~Hz}$ alpha band. Resting EEG was measured before and after stress induction by means of the MAST (Smeets et al., 2012). The MAST indeed generated robust increases in cortisol levels. The cortisol responses were moderated by gender, which is in line with the typically larger increases found in males compared to females in response to laboratory stressors (Meyer, Smeets, Giesbrecht, Quaedflieg, \& Merckelbach, 2013; for review see Kudielka et al., 2009). We found that higher left hemispheric activity at baseline was associated with lower stress-induced cortisol levels (AUCi), an effect that was specific to the sites F4-F3 and was only significant when IAF was used. Besides, we found higher baseline $\mathrm{FA}_{\mathrm{F} 8-\mathrm{F} 7}$ to correlate with higher BAS and lower BIS scores. Meanwhile, the stress induction did not result in a change in FA, which suggests that individual FA might reflect a trait-like characteristic that relates to cortisol reactivity to a stressor.

The finding that IAF based baseline $\mathrm{FA}_{\mathrm{F} 4-\mathrm{F} 3}$ was associated with lower stress-induced cortisol levels (AUCi) is in line with our
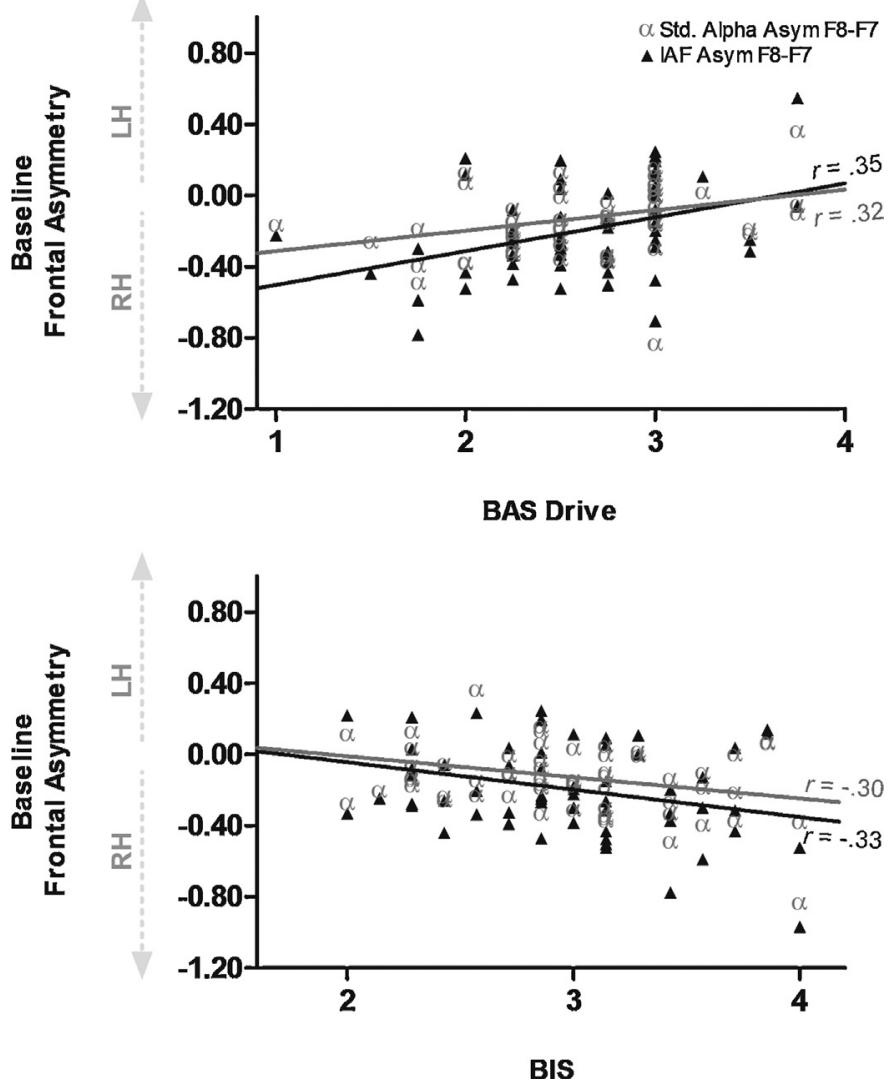

Fig. 5. Association between frontal asymmetry and behavioural activation. Baseline asymmetry at F8-F7 was positively associated with the BAS drive subscale and negatively with BIS

expectations and agrees well with studies suggesting that left frontal activity is involved in the regulation of hormonal stress responses (Baeken et al., 2014; Davidson, 2000; Sullivan \& Gratton, 2002). No association was found when FA was based on the standard $8-13 \mathrm{~Hz}$ alpha band, which is in agreement with previous studies investigating the relation between cortisol and FA in the standard alpha band (Hewig et al., 2008; Lewis et al., 2007; Tops et al., 2005). The mean of the IAF was not different from the centre of the standard alpha band indicating that the difference in sensitivity and reliability cannot be explained by the use of alpha sub-bands that are, across participants, consistently different from standard alpha. Our results support the idea that the individualized alpha band (IAF) is more reliable than standard alpha in the prediction of individual differences in the processing of stressors.

The current results suggest an association of BAS drive with baseline left lateral frontal activity and an association of BIS with baseline right lateral frontal activity (i.e., Asym ${ }_{\mathrm{F8}-\mathrm{F7}}$ ). Studies that have investigated the relation between BIS and frontal lateralization have yielded divergent findings, with most reporting weak or no association (Coan \& Allen, 2003a; De Pascalis, Cozzuto, Caprara, \& Alessandri, 2013; Harmon-Jones \& Allen, 1997; Hewig, Hagemann, Seifert, Naumann, \& Bartussek, 2006) while Sutton and Davidson (1997) also found a negative correlation. Nevertheless, in line with the current findings, all before mentioned studies hypothesized to find a negative correlation between BIS and FA. BIS is a motivationally complex concept (Amodio, Master, Yee, \& Taylor, 2008) that probably is reflected in a less robust relation with right-sided FA. In terms of BAS, relative left sided FA was related to more behavioural drive. This result is consistent with previous studies (Berkman \& Lieberman, 2010; De Pascalis, Varriale, \& D’Antuono, 2010; Tops \& Boksem, 2010) and more 
general with studies associating frontal asymmetry with overall behavioural activation (Amodio et al., 2008; Coan \& Allen, 2003a; Harmon-Jones \& Allen, 1997; Sutton \& Davidson, 1997). A noteworthy observation is that most studies found associations between the behavioural activation system and mid-frontal (F4-F3) locations corresponding to the dorsolateral prefrontal cortex (dIPFC; Herwig et al., 2003). Still, associations with lateral FA(F8-F7) have also been demonstrated in previous studies (e.g., Coan \& Allen, 2003a; Hewig et al., 2006), suggesting a more ventrolateral PFC source. Numerous neuroimaging studies have demonstrated opposite affective lateralized processing effects within specific areas of the PFC (see for reviews Miller, Crocker, Spielberg, Infantolino, \& Heller, 2013; Wager, Phan, Liberzon, \& Taylor, 2003), which could explain these divergent location findings and indicates the need to measure EEG at a high spatial density and combine EEG and fMRI (Davidson, 2004).

The finding that FA remained unaffected by stress is at first glance at odds with the study of Lewis et al. (2007) and the prior cortisol administration studies of Tops et al. (2005, 2006). Yet, Lewis et al. (2007) found different results when applying a region or a single electrode analysis and in line with our results, no effect of examination stress was found for the single electrode analysis of F4-F3. One explanation for the disparity with the studies of Tops et al. $(2005,2006)$ may be that exogenous cortisol administration activates the HPA-axis at a different level than a psychological stressor, which also increases the release of other hormones like catecholamines (Kudielka et al., 2009). Moreover, the timing of the EEG measurements could also account for the differential findings, as Tops et al. $(2005,2006)$ collapsed multiple asymmetry measurements over $30 \mathrm{~min}$ and $2 \mathrm{~h}$, respectively, whereas the current study did not. The current finding that stress induction did not result in a change in FA while at the same time individual $\mathrm{FA}_{\mathrm{F} 4-\mathrm{F} 3}$ predicted the cortisol response, suggests that individual FA reflects individual differences in a trait-like mechanism that moderates the cortisol stress response.

A few limitations of the current study should be noted. First, this study was performed in healthy subjects. Cortical asymmetry scores are expected to reflect more symmetrical activity in healthy subjects than in clinical populations (Gordon, Palmer, \& Cooper, 2010; Quinn, Rennie, Harris, \& Kemp, 2014) and therefore statistical results might be dampened. Second, FA was measured before and after the MAST, but not during the MAST. This was done because the MAST consists of mental arithmetic trials, and the induced cognitive effort could confound effects of stress on alpha activity when measured during the MAST. Thus, while we found no change in FA in response to the MAST, FA may still have transiently changed during stress. Finally, the present study is limited in generalizability by the fact that cortisol but no other measures of the stress response, like autonomic or subjective, were assessed.

In sum, the present findings suggest that baseline frontal alpha activity reflects a mechanism that has a moderating role in the fight-or-flight response to acute stress. Specifically, relatively left activation appears to be associated with resilience characterized by behavioural activation and neuroendocrine regulation. Thereby, this study contributes to the relatively sparse and inconsistent literature regarding the role of trait characteristics in moderating responses to state manipulation. Our data show that hemispheric asymmetry measures based on frontal alpha frequencies may serve as a better individual difference variable if they are based on individualized alpha frequencies than if they are based on standard alpha $(8-13 \mathrm{~Hz})$. Constructing frontal asymmetry on the individualized alpha band seems a promising avenue to the refinement and extension of our knowledge of the role of asymmetric hemispheric activation as a determinant of individuals' degree of stress resilience or vulnerability.

\section{Acknowledgements}

This work was supported by the Netherlands Organization for Scientific Research (NWO) (grant number 056-25-011) to TS. NWO had no further role in the study design; in the collection, analysis and interpretation of the data; in the writing of the report; and in the decision to submit the paper for publication. We are especially thankful to Marijke Hekkenberg, Loran van der Hoeven and Jonathan O'Keeffe for their help in collecting the data.

\section{References}

Allen, J. J. B., Coan, J. A., \& Nazarian, M. (2004). Issues and assumptions on the road from raw signals to metrics of frontal EEG asymmetry in emotion. Biological Psychology, 67, 183-218. http://dx.doi.org/10.1016/j.biopsycho.2004.03.007

Amodio, D. M., Master, S. L., Yee, C. M., \& Taylor, S. E. (2008). Neurocognitive components of the behavioral inhibition and activation systems: Implications for theories of self-regulation. Psychophysiology, 45, 11-19. http://dx.doi.org/10.1111/j.1469-8986.2007.00609.x

Baeken, C., Vanderhasselt, M. A., Remue, J., Rossi, V., Schiettecatte, J., Anckaert, E. et al. (2014). One left dorsolateral prefrontal cortical HF-rTMS session attenuates HPA-system sensitivity to critical feedback in healthy females. Neuropsychologia, 57, 112-121. http://dx.doi.org/10.1016/j.neuropsychologia.2014.02.019

Bazanova, O. M., \& Vernon, D. (2014). Interpreting EEG alpha activity. Neuroscience and Biobehavioral Reviews, 44C, 94-110. http://dx.doi.org/10.1016/ j.neubiorev.2013.05.007

Berkman, E. T., \& Lieberman, M. D. (2010). Approaching the bad and avoiding the good: Lateral prefrontal cortical asymmetry distinguishes between action and valence. Journal of Cognitive Neuroscience, 22, 1970-1979. http://dx.doi.org/10.1162/jocn.2009.21317

Buss, K. A., Schumacher, J. R. M., Dolski, I., Kalin, N. H., Goldsmith, H. H., \& Davidson, R. J. (2003). Right frontal brain activity, cortisol, and withdrawal behavior in 6-month-old infants. Behavioral Neuroscience, 117, 11-20. http://dx.doi.org/10.1037/0735-7044.117.1.11

Carver, C. S., \& White, T. L. (1994). Behavioral-inhibition, behavioral activation, and affective responses to impending reward and punishment: the BIS/BAS Scales. Journal of Personality and Social Psychology, 67, 319-333. http://dx.doi.org/10.1037/0022-3514.67.2.319

Coan, J. A., \& Allen, J. J. B. (2003a). Frontal EEG asymmetry and the behavioral activation and inhibition systems. Psychophysiology, 40, 106-114. http://dx.doi.org/10.1111/1469-8986.00011

Coan, J. A., \& Allen, J. J. B. (2003b). The state and trait nature of frontal EEG asymmetry in emotion. In A. KH, \& R. J. Davidson (Eds.), The asymmetrical brain (pp. 565-616). Cambridge, MA/London, England: The MIT Press.

Coan, J. A., \& Allen, J. J. B. (2004). Frontal EEG asymmetry as a moderator and mediator of emotion. Biological Psychology, 67, 7-49. http://dx.doi.org/10.1016/ j.biopsycho.2004.03.002

Coan, J. A., Allen, J. J. B., \& McKnight, P. E. (2006). A capability model of individual differences in frontal EEG asymmetry. Biological Psychology, 72, 198-207. http://dx.doi.org/10.1016/j.biopsycho.2005.10.003

Davidson, R. J. (2000). Affective style, psychopathology, and resilience: Brain mechanisms and plasticity. American Psychologist, 55, 1196-1214.

Davidson, R. J. (2004). What does the prefrontal cortex do in affect: Perspectives on frontal EEG asymmetry research. Biological Psychology, 67, 219-233. http://dx.doi.org/10.1016/j.biopsycho.2004.03.008

De Pascalis, V., Varriale, V., \& D'Antuono, L. (2010). Event-related components of the punishment and reward sensitivity. Clinical Neurophysiology: Official Journal of the International Federation of Clinical Neurophysiology, 121, 60-76. http://dx.doi.org/10.1016/j.clinph.2009.10.004

De Pascalis, V., Cozzuto, G., Caprara, G. V., \& Alessandri, G. (2013). Relations among EEG-alpha asymmetry, BIS/BAS, and dispositional optimism. Biological Psychology, 94, 198-209. http://dx.doi.org/10.1016/j.biopsycho.2013.05.016

Doppelmayr, M., Klimesch, W., Pachinger, T., \& Ripper, B. (1998). Individual differences in brain dynamics: Important implications for the calculation of event-related band power. Biological Cybernetics, 79, 49-57. http://dx.doi.org/10.1007/s004220050457

Gasser, T., Bacher, P., \& Steinberg, H. (1985). Test-retest reliability of spectral parameters of the EEG. Electroencephalography and Clinical Neurophysiology, 60, 312-319.

Goodman, R. N., Rietschel, J. C., Lo, L. C., Costanzo, M. E., \& Hatfield, B. D. (2013). Stress, emotion regulation and cognitive performance: The predictive contributions of trait and state relative frontal EEG alpha asymmetry. International Journal of Psychophysiology, 87, 115-123. http://dx.doi.org/10.1016/j.ijpsycho.2012.09.008

Gordon, E., Palmer, D. M., \& Cooper, N. (2010). EEG alpha asymmetry in schizophrenia, depression PTSD, panic disorder, ADHD and conduct disorder. Clinical EEG and Neuroscience, 41, 178-183.

Gratton, G., Coles, M. G., \& Donchin, E. (1983). A new method for off-line removal of ocular artifact. Electroencephalography and Clinical Neurophysiology, 55, $468-484$.

Harmon-Jones, E., \& Allen, J. J. B. (1997). Behavioral activation sensitivity and resting frontal EEG asymmetry: Covariation of putative indicators related to risk for mood disorders. Journal of Abnormal Psychology, 106, 159-163. http://dx.doi.org/10.1037/0021-843x.106.1.159 
Harmon-Jones, E., Gable, P. A., \& Peterson, C. K. (2010). The role of asymmetric frontal cortical activity in emotion-related phenomena: A review and update. Biological Psychology, 84, 451-462.

Heller, W. (1993). Neuropsychological mechanisms of individual differences in emotion, personality, and arousal. Neuropsychology, 7, 476-489.

Hewig, J., Hagemann, D., Seifert, J., Naumann, E., \& Bartussek, D. (2006). The relation of cortical activity and BIS/BAS on the trait level. Biological Psychology, 71, 42-53. http://dx.doi.org/10.1016/j.biopsycho.2005.01.006

Hewig, J., Schlotz, W., Gerhards, F., Breitenstein, C., Lurken, A., \& Naumann, E. (2008) Associations of the cortisol awakening response (CAR) with cortical activation asymmetry during the course of an exam stress period. Psychoneuroendocrinology, 33, 83-91. http://dx.doi.org/10.1016/j.psyneuen.2007.10.004

Herwig, U., Satrapi, P., \& Schonfeldt-Lecuona, C. (2003). Using the international 10-20 EEG system for positioning of transcranial magnetic stimulation. Brain Topography, 16, 95-99.

Jackson, D. C., Mueller, C. J., Dolski, I., Dalton, K. M., Nitschke, J. B., Urry, H. L., et al (2003). Now you feel it, now you don't: Frontal brain electrical asymmetry and individual differences in emotion regulation. Psychological Science, 14, 612-617.

Kalin, N. H., Larson, C., Shelton, S. E., \& Davidson, R. J. (1998). Asymmetric fronta brain activity, cortisol, and behavior associated with fearful temperament in rhesus monkeys. Behavioral Neuroscience, 112, 286-292.

Klimesch, W. (1999). EEG alpha and theta oscillations reflect cognitive and memory performance: A review and analysis. Brain Research Reviews, 29, 169-195. http://dx.doi.org/10.1016/S0165-0173(98)00056-3

Klimesch, W., Schimke, H., \& Pfurtscheller, G. (1993). Alpha frequency, cognitive load and memory performance. Brain Topography, 5, 241-251. http://dx.doi.org/10.1007/BF01128991

Kudielka, B. M., Hellhammer, D. H., \& Kirschbaum, C. (2007). Ten years of research with the Trier Social Stress Test-revisited. In E. Harmon-Jones, \& P. Winkielma (Eds.), Social neuroscience: Integrating biological and psychological explanations of social behavior (pp. 56-83). New York, NY, US: The Guilford Press.

Kudielka, B. M., Hellhammer, D. H., \& Wust, S. (2009). Why do we respond so differently? Reviewing determinants of human salivary cortisol responses to challenge. Psychoneuroendocrinology, 34, 2-18. http://dx.doi.org/10.1016 j.psyneuen.2008.10.004

Lewis, R. S., Weekes, N. Y., \& Wang, T. H. (2007). The effect of a naturalistic stressor on frontal EEG asymmetry, stress, and health. Biological Psychology, 75, 239-247. http://dx.doi.org/10.1016/j.biopsycho.2007.03.004

Lueken, U., Leisse, M. Mattes, K., Naumann, D., Wittling, W. \& Schweiger, E. (2009). Altered tonic and phasic cortisol secretion following unilateral stroke. Psychoneuroendocrinology, 34, 402-412. http://dx.doi.org/10.1016/ j.psyneuen.2008.10.002

Meyer, T., Smeets, T., Giesbrecht, T., Quaedflieg, C. W. E. M., \& Merckelbach, H. (2013) Acute stress differentially affects spatial configuration learning in high and low cortisol-responding healthy adults. European Journal of Psychotraumatology, 4 http://dx.doi.org/10.3402/ejpt.v4i0.19854

Meyer, T., Quaedflieg, C. W. E. M., Giesbrecht, T., Meijer, E. H., Abiad, S., \& Smeets, T. (2014). Frontal EEG asymmetry as predictor of physiological responses to aversive memories. Psychophysiology, 51, 853-865. http://dx.doi.org $10.1111 /$ psyp. 12230

Miller, G. A., Crocker, L. D., Spielberg, J. M., Infantolino, Z. P., \& Heller, W. (2013) Issues in localization of brain function: The case of lateralized frontal cortex in cognition, emotion, and psychopathology. Frontiers in Integrative Neuroscience 7, 2. http://dx.doi.org/10.3389/fnint.2013.00002

Papousek, I., Reiser, E. M., Weber, B., Freudenthaler, H. H., \& Schulter, G. (2012). Frontal brain asymmetry and affective flexibility in an emotional contagion paradigm. Psychophysiology, 49, 489-498. http://dx.doi.org/10.1111/ j.1469-8986.2011.01324.x

Perez-Edgar, K., Kujawa, A., Nelson, S. K., Cole, C., \& Zapp, D. J. (2013). The relation between electroencephalogram asymmetry and attention biases to threat at baseline and under stress. Brain and Cognition, 82, 337-343. http://dx.doi.org/10.1016/j.bandc.2013.05.009

Pfurtscheller, G., Stancak, A., \& Neuper, C. (1996). Event-related synchronization (ERS) in the alpha band - an electrophysiological correlate of cortical idling: A review. International Journal of Psychophysiology, 24, 39-46. http://dx.doi.org/10.1016/S0167-8760(96)00066-9

Pruessner, J. C., Kirschbaum, C., Meinlschmid, G., \& Hellhammer, D. H. (2003). Two formulas for computation of the area under the curve represent measures of total hormone concentration versus time-dependent change. Psychoneuroendocrinology, 28, 916-931. http://dx.doi.org/10.1016/S0306-4530(02)00108-7

Quinn, C. R. Rennie, C. J., Harris, A. W., \& Kemp, A. H. (2014). The impact of melancholia versus non-melancholia on resting-state, EEG alpha asymmetry: Electrophysiological evidence for depression heterogeneity. Psychiatry Research 215, 614-617. http://dx.doi.org/10.1016/j.psychres.2013.12.049

Rilling, J. K., Winslow, J. T., O’Brien, D., Gutman, D. A., Hoffman, J. M., \& Kilts, C. D. (2001). Neural correlates of maternal separation in Rhesus monkeys. Biological Psychiatry, 49, 146-157.

Smeets, T. Cornelisse, S., Quaedflieg, C. W. E. M., Meyer, T., Jelicic, M. \& Merckelbach, H. (2012). Introducing the Maastricht Acute Stress Test (MAST): A quick and non-invasive approach to elicit robust autonomic and glucocorticoid stress responses. Psychoneuroendocrinology, 37, 1998-2008. http://dx.doi.org/10.1016/j.psyneuen.2012.04.012

Sullivan, R. M. (2004). Hemispheric asymmetry in stress processing in rat prefrontal cortex and the role of mesocortical dopamine. Stress: The International Journal on the Biology of Stress, 7, 131-143. http://dx.doi.org 10.1080/102538900410001679310

Sullivan, R. M., \& Gratton, A. (2002). Prefrontal cortical regulation of hypothalamic-pituitary-adrenal function in the rat and implications for psychopathology: Side matters. Psychoneuroendocrinology, 27, 99-114

Sutton, S. K., \& Davidson, R. J. (1997). Prefrontal brain asymmetry: A biological substrate of the behavioral approach and inhibition systems. Psychological Science, 8, 204-210. http://dx.doi.org/10.1111/j.1467-9280.1997.tb00413.x

Tomarken, A. J., Davidson, R. J., Wheeler, R. E., \& Doss, R. C. (1992). Individual differences in anterior brain asymmetry and fundamental dimensions of emotion. Journal of Personality and Social Psychology, 62, 676-687.

Tomarken, A. J., Davidson, R. J., Wheeler, R. E., \& Kinney, L. (1992). Psychometric properties of resting anterior EEG asymmetry - temporal stability and internal consistency. Psychophysiology, 29, 576-592. http://dx.doi.org/10.1111/ j.1469-8986.1992.tb02034.x

Tops, M., \& Boksem, M. A. (2010). Absorbed in the task: Personality measures predict engagement during task performance as tracked by error negativity and asymmetrical frontal activity. Cognitive Affective and Behavioral Neuroscience, 10, 441-453. http://dx.doi.org/10.3758/CABN.10.4.441

Tops, M., Wijers, A. A., van Staveren, A. S. J., Bruin, K. J., Den Boer, J. A., Meijman T. F., et al. (2005). Acute cortisol administration modulates EEG alpha asymmetry in volunteers: Relevance to depression. Biological Psychology, 69, 181-193. http://dx.doi.org/10.1016/j.biopsycho.2004.07.005

Tops, M., van Peer, J. M., Wester, A. E., Wijers, A. A., \& Korf, J. (2006). State-dependent regulation of cortical activity by cortisol: An EEG study. Neuroscience Letters, 404 39-43. http://dx.doi.org/10.1016/j.neulet.2006.05.038

Velo, J. R., Stewart, J. L., Hasler, B. P., Towers, D. N., \& Allen, J. J. B. (2012). Should it matter when we record? Time of year and time of day as factors influencing frontal EEG asymmetry. Biological Psychology, 91, 283-291.

Wager, T. D., Phan, K. L., Liberzon, I., \& Taylor, S. F. (2003). Valence, gender, and lateralization of functional brain anatomy in emotion: A meta-analysis of findings from neuroimaging. Neuroimage, 19, 513-531.

Wittling, W., \& Pfluger, M. (1990). Neuroendocrine hemisphere asymmetries: Salivary cortisol secretion during lateralized viewing of emotion-related and neutra films. Brain and Cognition, 14, 243-265. 